\title{
Adverse Events of Exchange Transfusion in Neonatal Hyperbilirubinemia
}

\author{
Chitlangia $\mathbf{M}^{1}$, Shah $\mathbf{G S}^{2}$, Poudel $\mathbf{P}^{3}$, Mishra OP
}

\begin{abstract}
Introduction: Jaundice is an important problem during neonatal period. When total serum bilirubin (TSB) level exceeds a critical limit, it crosses the blood brain barrier and results into bilirubin encephalopathy. The main aim of therapy for neonatal hyperbilirubinemia is prevention of bilirubin encephalopathy by phototherapyand/or exchange transfusion. The aims of this study were to evaluate the efficacy of exchange transfusion (ET) and observe the adverse events during and following three days of ET in neonates with hyperbilirubinemia. Materials and Method: Hospital based cross-sectional descriptive study. All neonates admitted to neonatal intensive care unit and /or paediatric wards of a tertiary- care centre between September 2010 to March 2012, requiring ET were enrolled. Results: A total of 139 ETs were performed in 120 neonates. The common causes were ABO incompatibility (30.8\%), prematurity (30.8\%), idiopathic $(27.5 \%), \mathrm{Rh}$ isoimmunization (6.7\%) and cephalhematoma (4.2\%). Mean pre- ET total serum bilirubin (TSB) was $24.2 \mathrm{mg} \%$ $\mathrm{dL}$. There was $58 \%$ reduction in TSB in post ET and $31 \%$ net reduction in $6 \mathrm{hr}$ post ET. Term and preterm neonates showed equal percentage of TSB reduction. Respiratory distress (10.8\%) and bradycardia (6.7\%) were the common adverse events during, and hypocalcemia (98.3\%) and thrombocytopenia (34.2\%) in 3 days following ET. The sick neonates had significantly higher incidence of thrombocytopenia $(p=0.031)$, respiratory distress $(p=0.009)$, apnea $(p<0.001)$ and cardiorespiratory arrest $(p<0.001)$. Overall mortality was $4.2 \%$, and non-survivors were mostly low birth weight, born outside the present hospital and had higher incidence of adverse events. Conclusion: Exchange transfusion is an effective intervention in reducing the serum bilirubin level. However, these neonates require monitoring of ionised calcium and thrombocytopenia. Sick neonates had higher incidence of adverse events than healthy and close clinical monitoring is needed to improve the outcome.
\end{abstract}

Key words: exchange transfusion, neonatal hyperbilirubinemia, adverse events

\section{Introduction}

aundice is an important problem during neonatal period, especially in the first week of life ${ }^{1}$. The serum bilirubin level varies with birth
'Dr. Mohit Chitlangia, MBBS, MD, Department of Paediatrics and Adolescent Medicine, BP Koirala Institute of Health Sciences (BPKIHS), ${ }^{2} \mathrm{Dr}$. Gauri S Shah, MBBS, MD, Professor and Head of Department of Paediatrics and Adolescent Medicine, BPKIHS, ${ }^{3}$ Dr. Prakash Poudel, MBBS, MD, Associate Professor, Department of Paediatrics and Adolescent Medicine, BPKIHS, Dharan, Nepal, ${ }^{4} \mathrm{Dr}$. Om P Mishra, MBBS, MD, Professor, Department of Paediatrics, Institute of Medical Sciences, Banaras Hindu University, Varanasi, India.

\section{Address for correspondence}

Dr. Gauri S Shah

Professor and Head, Department of Paediatrics and Adolescent Medicine,

BPKIHS, Dharan, Nepal

Tel: +977-9842415770, Fax: +977-25520129

E-mail: gaurishankarshah@live.com

\section{How to cite}

Chitlangia M, Shah GS, Poudel P, Mishra OP. Adverse Events of Exchange Transfusion in Neonatal Hyperbilirubinemia. J Nepal Paediatr Soc 2014;34(1):7-13.

doi: http://dx.doi.org/10.3126/jnps.v34i1.9030

This work is licensed under a Creative Commons Attribution 3.0 License.

\section{(c) (i)}

weight, gestational age, chronological age and internal milieu of the body. When total serum bilirubin (TSB) level exceeds a critical limit, it crosses the blood brain barrier and results into bilirubin encephalopathy ${ }^{2}$. About $50 \%$ of the term and $80 \%$ of preterm neonates develop jaundice during early neonatal period ${ }^{3}$.

About $0.02-0.16 \%$ of neonates develop extreme hyperbilirubinemia ${ }^{4}$. In developed countries, the incidence of severe jaundice 
and associated bilirubin encephalopathy is low. However, in developing countries, this preventable disease still occurs in a significant proportion of neonates ${ }^{5}$. Several clinical factors have been associated in causation of severe jaundice including breast milk feeding, ABO incompatibly, G6PD deficiency, East Asian Ethnicity and cephalhematoma ${ }^{6}$.

The main aim of therapy for neonatal hyperbilirubinemia is prevention of bilirubin encephalopathy by phototherapy and/or exchange transfusion (ET). The modality of exchange transfusion in the treatment of hyperbilirubinemia was a proven therapy, probably two decades back, however with the availability of highly effective double surface and LED phototherapy and administration of intravenous immunoglobulin G (IVIg) in prevention of isoimmunization / blood group incompatibility, the number of exchange transfusions have significantly reduced ${ }^{7}$. However, despite having adverse events, it leads to a rapid decline in serum bilirubin levels in symptomatic neonates sufficient enough to minimize the brain damage ${ }^{8}$. We report our observations on efficacy, adverse events and factors contributing to mortality related with ET performed for the treatment of neonatal hyperbilirubinemia at a tertiary-care centre.

\section{Materials and Methods}

This study was conducted at tertiary-care centre of a teaching hospital. All neonates presenting with indirect hyperbilirubinemia requiring ET during the period of September 2010 to March 2012 were included. The criteria for ET for the management of hyperbilirubinemia were followed as per American Academy of Pediatrics 2004 guidelines ${ }^{6}$. Neonates who had undergone exchange transfusion for reasons other than hyperbilirubinemia and partial ET were excluded from the study. The protocol of the study was approved by Institute ethical review board and informed consent was taken from parent of each neonate.

Detailed baseline characteristics and clinical findings were recorded in a pre-designed proforma. Cases were subjected to investigations which included hematocrit, hemoglobin, total and differential leukocyte counts, platelets count and peripheral blood smear, reticulocyte count and direct Coombs test for features of hemolysis. $\mathrm{ABO}$ and $\mathrm{Rh}$ blood grouping of both baby and mother were done. Biochemical parameters included blood glucose, total and direct serum bilirubin and ionized calcium levels.
$\mathrm{Rh}$ disease was defined as jaundice in Rh positive newborns born to Rh negative mothers with elevated antibody titres to the Rh antigen and evidence of hemolysis. ABO disease was attributed as cause of jaundice in newborns with positive direct Coombs test against the $\mathrm{A}$ or $\mathrm{B}$ antigens from type $\mathrm{O}$ mothers. An infant was considered healthy if jaundice was the only problem and the baby was active and taking feeds adequately, as opposed to sick neonates who had ongoing illnesses such as birth asphyxia, meconium aspiration syndrome, respiratory distress syndrome that required treatment prior to or at the same time ET. The adverse events which occurred during and within 3 days of the procedure were observed and managed accordingly.

The push-pull method of double volume exchange transfusion $(160 \mathrm{ml} / \mathrm{kg}$ ) with stored whole blood of $<5$ days duration having citrate-dextrose phosphate adenosine-1 (CDPA) anticoagulant was used. Whole blood collected in CDPA compatible to mother and baby was used. Removal and infusion of small aliquots of blood was performed in all neonates through umbilical vein catheterization as per the standard published guidelines ${ }^{8}$. The catheter was removed after the procedure. Peripheral vein was not used in any patient ${ }^{9}$.

In sick neonates, supportive treatment in the form of intravenous fluids, $\mathrm{O}_{2}$ inhalation, empiric antibiotics (Ampicillin + Amikacin) were given. The antibiotics were changed after culture report as per antimicrobial sensitivity pattern. Vasopressors (Dopamine and / or Dobutamine) were used wherever required. Biochemical abnormalities such as hypoglycemia and hypocalcemia were corrected before taking up the ET. However, no intermittent infusions of calcium were given during the procedure as per our NICU protocol. The IVIg was not used in any neonate with $\mathrm{Rh}$ isoimmunization because of high cost and nonaffordability in our patients.

\section{Monitoring}

The neonates were monitored during and 3 days following ET for heart rate, respiratory rate, temperature, $\mathrm{SpO}_{2}$ and ECG. Phototherapy was uniformly continued in post ET period till the level decreased to a safe limit. Serum bilirubin, hematocrit, platelets, blood glucose and ionized calcium were measured post and $6 \mathrm{hr}$ post ET period. ET-related adverse events were defined as any complication which was not present before ET and occurred during and within three days after the exchange. Complications 
observed were thrombocytopenia (platelet count $<100000 / \mathrm{mm} 3$ ), hypocalcemia (plasma ionized calcium $<1 \mathrm{mmol} / \mathrm{L}$ ), hypoglycemia (serum glucose $<40 \mathrm{mg} / \mathrm{dL}$ ), apnea and cardiorespiratory arrest.

\section{Statistical analysis}

Data were analyzed using the SPSS version 16.0. Chi-square and Fisher Exact tests were applied to compare the data of proportions and Student's $t$-test was used for quantitative variables. A p value of less than 0.05 was considered as statistically significant.

\section{Results}

There were 120 neonates, in whom 139 ETs were performed. Demographic characteristics of the neonates are shown in Table 1 . There were 53 preterm and 67 term neonates. The term neonates had significantly higher mean gestation, body weight and required longer duration of ET than preterm $(p<0.001)$. The other parameters such as age at ET, gender, race, birth order and place of delivery were comparable between preterm and term neonates.

The predominant causes of hyperbilirubinemia were $A B O$ incompatibility $(30.8 \%)$ and prematurity (30.8\%). Rh incompatibility and cephalhematoma accounted for $6.7 \%$ and $4.2 \%$ of cases, respectively. No cause could be ascertained in $27.5 \%$ of cases and they were categorized as idiopathic group. ET was done once in 106 (88.3\%), twice in 11 (9.2\%), thrice in $2(1.7 \%)$ and 5 times in $1(0.8 \%)$ neonates.

The mean serum bilirubin levels in study subjects are presented in Table 2. The bilirubin levels showed significant decline in post ET and $6 \mathrm{hr}$ post ET period in comparison to pre- ET value $(p<0.001)$. The mean reductions in serum bilirubin levels were $14.2 \pm 3.9 \mathrm{mg} /$ $\mathrm{dL}$ in post-ET and $7.7 \pm 4.1 \mathrm{mg} / \mathrm{dL}$ in $6 \mathrm{hr}$ post-ET period (Fig. 1). The term neonates had significantly higher levels of mean serum bilirubin at all stages (pre- ET, post ET and $6 \mathrm{hr}$ post ET) when compared with preterm $(p<0.001)$. However, the degree of reduction in serum bilirubin level was comparable between preterm and term babies.

A total of 11 cases were categorized as sick neonates. There were no significant differences in mean serum bilirubin levels in post $(56.1 \pm 6.1 \mathrm{vs}$. $58.6 \pm 10.3, \mathrm{p}=0.430)$ and $6 \mathrm{hr}$ post- ET $(26.1 \pm 22.4 \mathrm{vs}$ $31.9 \pm 14.2, p=0.225)$ period between sick and healthy neonates.

Of 120 neonates, adverse events occurred in $19(15.8 \%)$ during the ET. The common events were respiratory distress in $13(10.8 \%)$ and bradycardia in $8(6.7 \%)$ cases. Apnea, cardio-respiratory arrest and hypoglycaemia were observed in $2.5 \%, 1.7 \%$, and $0.8 \%$ of cases, respectively. No significant differences in the occurrence of events between preterm and term babies were observed during ET.

The neonates had more than one adverse events and thus 203 adverse events occurred in 120 babies (ratio being 1.69) during three days following ET, as shown in Table 3. The common adverse events were hypocalcemia in $98.3 \%$ (symptomatic in 14.2\%) and thrombocytopenia in $34.2 \%$ (symptomatic in $1.7 \%$ ) of neonates. Other events such as hypoglycemia (5\%), respiratory distress (9.2\%) and apnea (5.8\%) also occurred following exchange transfusion. Almost equal proportion of preterm and term babies developed adverse events.

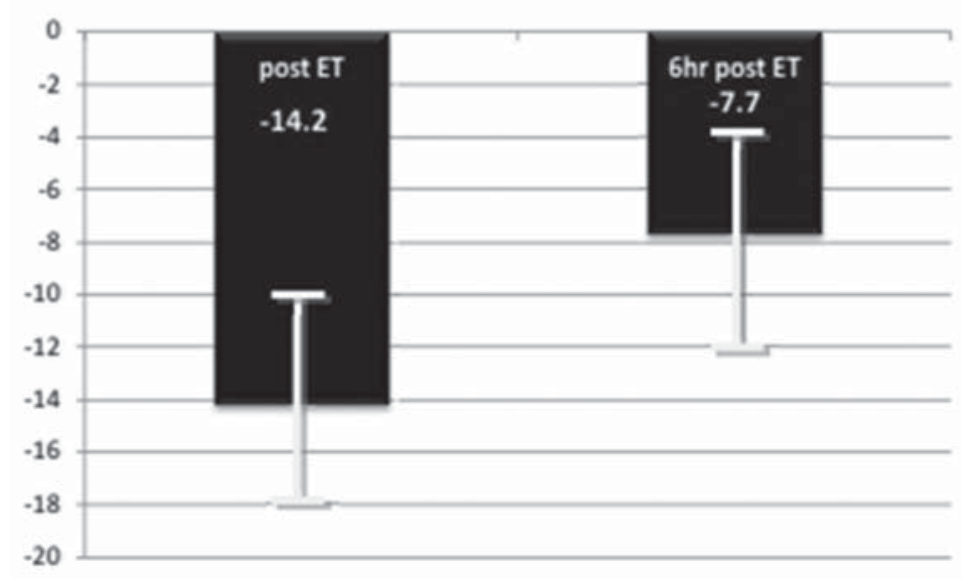

Fig 1 
Table 1: Basic demographic of characteristics patients according to gestational age $(n=120)$

\begin{tabular}{|c|c|c|c|c|c|}
\hline \multirow{2}{*}{\multicolumn{2}{|c|}{ Characteristics }} & \multicolumn{2}{|c|}{ Gestational Age } & \multirow{2}{*}{ Total } & \multirow{2}{*}{$p$-value } \\
\hline & & $<37$ weeks $(n=53)$ & $\geq 37$ weeks $(n=67)$ & & \\
\hline \multicolumn{2}{|c|}{$\begin{array}{l}\text { Gestation (wks) } \\
\text { (mean } \pm \text { SD) }\end{array}$} & $33.1 \pm 1.8$ & $38.90 \pm 0.98$ & $36.64 \pm 3.2$ & $<0.001^{*}$ \\
\hline \multicolumn{2}{|c|}{$\begin{array}{l}\text { Body weight }(\mathrm{g}) \\
\text { (mean } \pm \text { SD) }\end{array}$} & $\begin{array}{c}1673.7 \pm \\
351.4\end{array}$ & $\begin{array}{c}2870.75 \pm \\
519.86\end{array}$ & $\begin{array}{c}2342.08 \pm \\
748.42\end{array}$ & $<0.001^{¥}$ \\
\hline \multicolumn{2}{|c|}{$\begin{array}{l}\text { ET duration (min) } \\
(\text { mean } \pm S D)\end{array}$} & $62.9 \pm 10.4$ & $74.03 \pm 18.03$ & $69.13 \pm 16.08$ & $<0.00^{¥}$ \\
\hline \multicolumn{2}{|c|}{$\begin{array}{l}\text { Age at ET (days) } \\
\text { (mean } \pm \text { SD) }\end{array}$} & $5.26 \pm 1.2$ & $5.63 \pm 2.69$ & $5.5 \pm 2.2$ & $0.369^{¥}$ \\
\hline \multirow{2}{*}{$\begin{array}{l}\text { Gender } \\
\mathrm{n}(\%)\end{array}$} & Male & $28(52.8)$ & $42(62.7)$ & $70(58.3)$ & \multirow{2}{*}{$0.277^{x}$} \\
\hline & Female & $25(47.2)$ & $25(37.3)$ & $50(41.7)$ & \\
\hline \multirow{2}{*}{$\begin{array}{l}\text { Race } \\
\text { n (\%) }\end{array}$} & Mongolian & $17(32.1)$ & $23(34.3)$ & $40(33.3)$ & \multirow{2}{*}{$0.795^{\not}$} \\
\hline & Non-Mongolian & $36(67.9)$ & $44(65.7)$ & $80(66.7)$ & \\
\hline \multirow{3}{*}{$\begin{array}{l}\text { Birth } \\
\text { Order } \\
\text { n (\%) }\end{array}$} & First Born & $40(75.5)$ & $52(77.6)$ & $92(76.7)$ & \multirow[t]{3}{*}{$0.842^{\not}$} \\
\hline & Second & $9(17)$ & 10(14.9) & $19(15.8)$ & \\
\hline & Third and more & $4(7.5)$ & $5(8.8)$ & $9(7.5)$ & \\
\hline \multirow{2}{*}{$\begin{array}{l}\text { Place of } \\
\text { Delivery } \\
\text { n (\%) }\end{array}$} & Home & $12(22.6)$ & $16(23.9)$ & $28(23.3)$ & \multirow[b]{2}{*}{$0.873^{\not}$} \\
\hline & Hospital & $41(77.4)$ & $51(76.1)$ & $92(76.7)$ & \\
\hline \multirow{2}{*}{$\begin{array}{l}\text { Inborn/ } \\
\text { outborn } \\
\text { n (\%) }\end{array}$} & Inborn & $26(49.1)$ & $19(28.4)$ & $45(37.5)$ & \multirow[b]{2}{*}{$0.020^{\text {म }}$} \\
\hline & Outborn & $27(50.9)$ & $48(71.6)$ & $75(62.5)$ & \\
\hline \multirow{3}{*}{$\begin{array}{l}\text { Mode of } \\
\text { Delivery } \\
n(\%)\end{array}$} & Spontaneous Vaginal & $40(75.5)$ & $48(71.6)$ & $88(73.3)$ & \multirow{3}{*}{$0.509^{\not}$} \\
\hline & Caeserean & $11(20.8)$ & $13(19.4)$ & $24(20.0)$ & \\
\hline & Instrumental & $2(3.8)$ & $6(9.0)$ & $8(6.70)$ & \\
\hline \multicolumn{2}{|c|}{ Breast Feeding $\mathrm{n}(\%)$} & $40(75.5)$ & $65(97)$ & $105(87.5)$ & $<0.001^{\text {모 }}$ \\
\hline
\end{tabular}

Table 2: Serum bilirubin levels ( $\mathrm{mg} / \mathrm{dl}$ ) in study subjects (mean $\pm \mathrm{SD}$ )

\begin{tabular}{|l|c|c|c|}
\hline Groups & $\begin{array}{c}\text { Preterm } \\
\mathrm{n}=\mathbf{5 3}\end{array}$ & $\begin{array}{c}\text { Term } \\
\mathrm{n}=\mathbf{6 7}\end{array}$ & $\boldsymbol{p}$ - value \\
\hline A. Pre ET & $20.4 \pm 3.9$ & $27.2 \pm 4.0$ & $<0.001^{*}$ \\
\hline B. Post ET & $8.5 \pm 2.5$ & $11.3 \pm 3.2$ & $0.001^{¥}$ \\
\hline C. 6 hr post ET & $13.7 \pm 3.0$ & $18.7 \pm 4.7$ & $<0.001^{*}$ \\
\hline
\end{tabular}

$¥=$ Student's t-test, Inter group comparisons are highly significant $(p<0.001)$

Table 3: Adverse events following 3 days of ET $(n=120)$

\begin{tabular}{|c|c|c|c|}
\hline \multirow{2}{*}{ Adverse events } & \multicolumn{2}{|c|}{$\begin{array}{l}\text { Gestational Age } \\
\text { (wks) }\end{array}$} & \multirow{2}{*}{$p$-value } \\
\hline & $\begin{array}{l}<37 \\
\mathrm{n}(\%)\end{array}$ & $\begin{array}{c}\geq 37 \\
\mathrm{n}(\%)\end{array}$ & \\
\hline Hypocalcemia & $53(100)$ & $65(97)$ & $0.205^{\not}$ \\
\hline Thrombocytopenia & $21(39.6)$ & 20 (29.9) & $0.262^{\text {口 }}$ \\
\hline Respiratory distress & $6(11.3)$ & $5(7.5)$ & $0.467^{x}$ \\
\hline Hypoglycaemia & $5(9.4)$ & $1(1.5)$ & $0.086^{f}$ \\
\hline Apnea & $5(9.4)$ & $2(3.0)$ & $0.239^{f}$ \\
\hline Death & $4(7.5)$ & $1(1.5)$ & $0.169^{f}$ \\
\hline Total & 103 & 100 & \\
\hline
\end{tabular}

DIC- Disseminated intravascular coagulation $\not$ - Chi- square test, $€$ - Fisher exact test 
Table 4: Adverse events following 3 days of ET in sick and healthy neonates

\begin{tabular}{|c|c|c|c|}
\hline Adverse events & $\begin{array}{c}\text { Healthy } \\
\text { (n=109) } \\
n(\%)\end{array}$ & $\begin{array}{c}\text { Sick } \\
(n=11) \\
n(\%)\end{array}$ & $p$-value \\
\hline Hypocalcemia & 107 (98.17) & $11(100)$ & $0.65^{\not p}$ \\
\hline Thrombocytopenia & 34 (31.19) & $7(63.64)$ & $0.031^{x}$ \\
\hline Respiratory distress & $7(6.42)$ & $4(36.36)$ & $0.009^{f}$ \\
\hline Hypoglycaemia & $5(4.59)$ & 1 (9.09) & $0.44^{f}$ \\
\hline Apnea & $2(1.83)$ & $5(45.45)$ & $<0.001^{f}$ \\
\hline Cardio respiratory arrest & $2(1.83)$ & $4(36.36)$ & $<0.001^{f}$ \\
\hline Death & $2(1.83)$ & $3(27.27)$ & $0.005^{f}$ \\
\hline
\end{tabular}

DIC- Disseminated intravascular coagulation $\not$ - Chi- square test $f$ - Fisher exact test

Table 4 shows adverse events in healthy and sick neonates following 3 days of exchange transfusion. The sick neonates had proportionately higher incidence of hypocalcemia (11), thrombocytopenia (11), apnea (5), respiratory distress (4), and cardio-respiratory arrest (4) in comparison to healthy babies. In sick neonates, there were significant fall in hematocrit in post ET $(p=0.038)$ and ionised calcium in $6 \mathrm{hr}$ post ET period $(p=0.013)$ in comparison to healthy neonates.

Seven neonates had early features of bilirubin encephalopathy (lethargy, hypotonia and poor sucking) and they were born outside the present hospital. The mean serum bilirubin level was 31.6 $\mathrm{mg} / \mathrm{dL}$. Majority of them belonged to non-Mongolian race $(71.4 \%)$, presented in less than seven days of postnatal life (71.4\%), had body weight between 2500 $4000 \mathrm{~g}(71.4 \%)$ and born at term gestation (85.7\%) by spontaneous vaginal delivery $(85.7 \%)$. The causes of hyperbilirubinemia were idiopathic in 4 (57.1\%), Rh incompatibility in 2 (28.6\%) and $A B O$ incompatibility in $1(14.3 \%)$ cases. Five neonates required ET once (71.4\%) and 1 required 3 times (14.3\%) and another 1 required 5 times (14.3\%).

During hospital stay, 106 (88.3\%) cases survived, 5 (4.2\%) died and 9 (7.5\%) left against medical advice. Significantly higher proportion of non-survivors were outborn (100\%), low birth weight $(80 \%)$ and belonged to sick category $(60 \%)$ and had hypoglycemia $(40 \%)$, apnea (40\%), and DIC (20\%) in comparison to survivors.

\section{Discussion}

Early detection and treatment of neonatal hyperbilirubinemia are essential in the prevention of bilirubin encephalopathy. The ET is an emergency procedure and the mean age at which it was performed was 5.5 days in the present study. This was somewhat late than reported by previous workers ${ }^{10,11,12}$ because patients reporting to our centre comes from far off places and there is late referral from peripheral health centres also.

The common causes of hyperbilirubinemia were prematurity and $\mathrm{ABO}$ incompatibility (30.8\% each). Steiner et al. ${ }^{7}$ found that about $28 \%$ of cases of ET was due to $A B O$ setting. However, Behjati et al. ${ }^{13}$ found $A B O(52 \%)$ and $\mathrm{Rh}(12 \%)$ incompatibility in higher proportion of their cases. Idiopathic group constituted the second most common cause. It may be possible that we may not be able to find any attributable cause in neonates with indirect hyperbilirubinemia and the range of idiopathic etiology varied from $13.9 \%$ to $36.4 \%$ in different studies earlier ${ }^{11,12,14}$. Majority of neonates were breast fed, as it is a regular practice to have exclusive breast feeding.

The ET was performed once in majority (88.3\%) of neonates and more than once in $11.7 \%$ of cases. The requirement of more than one ET was also reported by other workers ${ }^{12,15}$. Thirteen cases required ET 2-3 times and the major etiology was $A B O$ incompatibility while one baby required ET five times and the etiology was $\mathrm{Rh}$ isoimmunization. The IVIg could not be used in Rh isoimmunisation due to non- affordability.

As regard to efficacy of ET, overall there was significant decrease in mean serum bilirubin level in post ET and $6 \mathrm{hr}$ post ET period $(p<0.001)$. The similar trend was observed when comparisons were made in preterm and term babies. Further, we found that overall percentage reduction in serum bilirubin level was $58 \%$ from pre -ET level. Sakha et al. ${ }^{14}$ reported $61 \%$ reduction in bilirubin. By contrast, Bhat ${ }^{16}$ observed lower percent reduction in serum bilirubin level (40.3\%) in their study. Further, there was a rise in serum bilirubin level in $6 \mathrm{hr}$ post ET period despite continued phototherapy. The 
overall net reduction in serum bilirubin level was $31 \%$ in $6 \mathrm{hr}$ post ET period. Thus, ET removes about $60 \%$ of bilirubin from plasma, resulting in a clearance of 30 to $40 \%$ of bilirubin ${ }^{17}$.

Hypocalcemia (98.3\%) and thrombocytopenia (34.2\%) were the major adverse events following 3 days of ET, but mostly they were asymptomatic. Other authors $^{12,14}$ have observed much lower incidence of hypocalcemia (2.5-38\%). Unusually very high incidence of hypocalcemia observed in our study could be because of the fact that we did not use prophylactic calcium administration during the procedure unless it became symptomatic. Also, hypocalcemia has been associated with the use of CPDA-1 as an anticoagulant due to the binding of calcium by citrate. Thus, it appears that possibly these neonates require calcium supplementation during the procedure to avoid the occurrence of hypocalcemia The need for giving supplemental calcium is controversial. However, if 0.5 to $1.0 \mathrm{ml}$ of $10 \%$ intravenous calcium gluconate after each $100 \mathrm{ml}$ of exchange blood is used, it may reduce the incidence of hypocalcemia ${ }^{18}$. Thrombocytopenia (34.2\%) was another major adverse event observed and the exact cause remained uncertain. Besides ET, phototherapy can also cause thrombocytopenia and both together can lead to decrease in platelets count in these babies. However, treatment should be given due consideration especially if the neonates develop bleeding manifestations. The other events were hypoglycaemia, respiratory distress, apnea and cardio-respiratory arrest; posing additional problems requiring close monitoring during the procedure.

It was further observed that sick neonates had significantly higher incidence of thrombocytopenia, respiratory distress and life threatening events such as apnea and cardiorespiratory arrest in comparison to healthy babies; emphasizing the fact that they had already disturbed physiological status and ET further complicated the course. Therefore adequate attention should be paid for occurrence of such adverse events in sick neonates. All cases required ET once. However, Jackson ${ }^{19}$ reported that sick neonates needed multiple ETs in their studies.

Seven neonates had features of early bilirubin encephalopathy at presentation, requiring urgent ET. $\mathrm{Rh}$ and $\mathrm{ABO}$ incompatibility were present in three cases and no cause could be ascertained in four cases. Neurological features disappeared in majority of cases following ET; indicating the early performance of ET to avoid brain damage and future neurological sequelae.
Five neonates (4.2\%) died within $24 \mathrm{hr}$ of ET. Other studies have observed lower mortality rate (0.5$2.8 \%)^{20,21}$. The high mortality observed in our study could be due to that all of them were outborn and mostly low birth weight babies. The two neonates had features of bilirubin encephalopathy at presentation among non-survivors. They also had higher adverse events such as hypocalcemia, hypoglycemia and life threatening events (apnea and bradycardia). Therefore, adequate precautions are to be undertaken to correct such metabolic abnormalities in order to prevent lifethreatening complications and reduce mortality.

\section{Conclusion}

In conclusion, although the rate of adverse events associated with exchange transfusions was high, most events were asymptomatic. Hypocalcemia was found in almost all neonates followed by thrombocytopenia. Therefore intravenous calcium infusion during ET procedure may be required. However, despite these considerations, ET still remains an effective modality in reducing the neonatal hyperbilirubinemia and preventing bilirubin encephalopathy in developing countries where sick neonates are referred quite late to a tertiary-care centre.

Acknowledgement: Authors are thankful to Mr. D.D. Baral, Department of Community Medicine, BPKIHS, Dharan for his help in statistical analysis.

Conflict of interest: None

Funding: None

Permission from IRB: Yes

\section{References}

1. Maisels MJ, Kring E. Length of Stay, jaundice, and hospital readmission. Pediatrics 1998;101(6):9958.

2. Brown AK, Damus K, Kim MH et al. Factors relating to readmission of term and near-term neonates in the first-two weeks of life. Early Discharge Survey Group of the Health Professional Advisory Board of the Greater New York Chapter of the March of Dimes. J Perinat Med 1999;27(4):263-75.

3. Jardine LA, Woodgate P. Neonatal jaundice. Am Fam Physician 2012 ; 85(8):824-825.

4. Bhutani VK, Johnson LH, Keren R. Diagnosis and management of hyperbilirubinemia in the term neonate: for a safer first week. Pediatr Clin North Am 2004;51:843-61. 
5. Sgro M, Campbell D, Shah V. Incidence and causes of severe neonatal hyperbilirubinemia in Canada. Canadian Med Assoc J 2006;175(6):587-90.

6. American Academy of Pediatrics Practice Guidelines. Subcommittee on hyperbilirubinemia. management of hyperbilirubinemia in the newborn infant 35 weeks or more of gestation. Pediatrics 2004;114:297-316.

7. Steiner LA, Bizzarro MJ, Ehrenkranz RA, Gallagher PG. A decline in the frequency of neonatal exchange transfusions and its effect on exchangerelated morbidity and mortality. Pediatrics 2007;120(1):27- 32 .

8. Ip S, Chung M, Kulig J et al. An evidence-based review of important issues concerning neonatal hyperbilirubinemia. Pediatrics 2004;114:130-53.

9. Hsiao-Neng Chen, Meng-Luen Lee, Lon-Yen Tsao. Exchange transfusion using peripheral vessels is safe and effective in newborn infants. Pediatrics 2008;122:e905 -e910.

10. Sanpavat S. Exchange transfusion and its morbidity in ten-year period at King Chulalongkorn Hospital. J Med Assoc Thai 2005; 88:588-92.

11. Davutoğlu M, Garipardıç $M$, Güler $E$ et al. The etiology of severe neonatal hyperbilirubinemia and complications of exchange transfusion. Turk J Pediatr 2010;52: 163-6.

12. Bhat AW, Churoo BA, Iqbal $Q$ et al. Complication of exchange transfusion at a tertiary care hospital. Curr Pediatr Res 2011;15(2):97-9.
13. Behjati S, Sagheb S, Aryasepehr S et al. Adverse Events Associated with Neonatal Exchange Transfusion for Hyperbilirubinemia. Indian J Pediatr 2009;76:83-5.

14. Sakha SH, Gharehbaghi MM. Exchange transfusion in severe hyperbilirubinemia: an experience in northwest Iran. Turk J Pediatr 2010;52:367-71.

15. Badiee Z. Exchange transfusion in neonatal hyperbilirubinaemia: experience in Isfahan, Iran. Singapore Med J 2007;48(5):421-3.

16. Bhat RY. Management of Neonatal Hyperbilirubinemia- What is the Efficacy of Exchange Transfusion by Different Techniques? J Neonatol 2007;21(1):68-70.

17. Maissels MJ. Neonatal hyperbilirubinemia. In: Care of the high-risk neonate. 5th edition. W.B. Sounders. Philadelphia. 2001.pp 363-64.

18. Nelson N, Finnström O. Blood exchange transfusions in newborns, the effect on serum ionized calcium. Early human Dev 1988;18(23):157-64.

19. Jackson JC. Adverse events associated with exchange transfusion in healthy and ill newborns. Pediatrics 1997;99:e7.

20. Patra K, Storfer-Isser A, Siner B et al. Adverse events associated with neonatal exchange transfusion in the 1990s. J Pediatr 2004;144:626-31.

21. Choudhury HR, Hasan MA, Yasmin F.Outcome of neonatal hyperbilirubinemia in a Tertiary Care Hospital in Bangladesh. Malays J Med Sci 2010;17:40-44. 